\title{
Using Virtual Tours to Facilitate Sustainable Site Visits of Historic Sites
}

\author{
Benjamin H. George ${ }^{1}$
}

\begin{abstract}
Many university-level design programs send their students on travel trips to notable examples of design across the globe. However, it is increasingly expensive for both students and programs to commit to extensive travel, and the accelerated growth of global tourism has led to increased pressure on many sensitive historical sites. However, the use of virtual tours may provide a learning experience for students that provides many of the learning affordances of an on-site visit; but does so in a more sustainable manner by reducing financial costs for institutions and lower visitor numbers for historical sites. This paper reports the findings of a program using 360 -degree virtual tours in a landscape architecture history course to test students' ability to spatially encode a site. The results found that students who visit a site using a virtual tour have significantly improved spatial encoding and improved performance on testing of factual knowledge related to the site, suggesting that students experienced many of the similar learning affordances of being on site. This would indicate that virtual tours can provide an opportunity for universities to provide students with a sustainable learning opportunity similar to what would be achieved through a physical visit to a site.
\end{abstract}

Keywords: Landscape architecture history, constructivism, situated learning, visualization, virtual tour

\section{History and Instruction}

During the Age of Enlightenment, it was customary for young adults of prominent families to experience the history of European culture and art through a months-long trip known as the grand tour. This capstone experience was meant to provide an educational episode that could not be captured in the classroom and, ever since, travel has become an important element in education. In the fields of design, traveling to sites is viewed as a valuable way to ground students in the physical manifestation of design, and this is no truer than in the subject of design history. Despite the value that site visits can provide, history has traditionally been taught using an instructivist approach, a pedagogy based on the assumption that knowledge is an objective construct that can be transferred from the teacher to the student (Wilson and Wineburg 1988; Hartzler-Miller 2001). Most individuals are familiar with this form of instruction because they will have experienced it repeatedly in traditional classrooms: a teacher lectures at the front of the class with little pause for questions or interaction. This form of instruction creates a passive learning environment with little expectation for the student to participate in the learning process. Learning becomes monotonous and mundane because of the pedagogical focus on rote memorization and a lack of opportunities to engage and, as a result, students become disengaged from the learning process (Donovan and Bransford 2005; Mitsoni 2006). 
The teaching of landscape architecture history is not immune to trends of student disengagement. Michael (2007) identified history teaching in landscape architecture as a subject area that is currently experiencing an increasing amount of student disengagement and, perhaps as a result, degrading student understanding of landscape architecture history. Michael (2007) further found that, in the large majority of landscape architecture history courses, learning happens in a decontextualized environment reliant upon lectures and textbooks. This decontextualization is exacerbated by the nature of history as a subject that students are already both physically and chronologically separated from.

The constructivist approach to instruction offers an opportunity to rethink the way that history courses are taught. Constructivist theory is learner-centered, and posits that learners construct knowledge through interactions with the world around them, and that new knowledge is informed by, and built upon, the learner's existing knowledge (Dewey 1966; Piaget 1973; Driscoll 2005). In a constructivist learning environment, the learner is expected to be an active participant in the learning process through tasks such as exploration, evaluation and synthesis (Erstad 2002; Driscoll 2005; Eilouti 2007). Through these tasks the student develops a deeper understanding of the subject matter than would be possible using the passive instructivist approach (Land and Hannafin 2000). Importantly, the student ceases to be an information consumer, reliant upon the teacher as the sole source of information, and instead develops the skills and attributes necessary to become an information synthesizer and producer.

\section{Study Purpose}

This study examines the use of virtual tours in a landscape architecture history course in place of physical site visits as a method of creating a learning environment that contextualizes the curriculum, is more engaging for the student, and eliminates the need for physical site visits. The use of virtual tours is not new in education, though they have rarely been used in teaching history. Precedent exists in the field of architectural history (Carlucci 2007), and a handful of universities maintain a modest number of virtual tours of historic buildings. Virtual tours or panoramic imagery have also been used in other subject areas within both architecture (Ozcan 2000) and art history (Rountree, Hannah, and Wong 2004).

Previous studies using virtual tours or similar visualizations in way finding, cognitive mapping and spatial awareness have produced mixed results. Early studies suggested that spatial awareness in simulations was acquired in a similar manner and level to real-life settings (Bliss, Tidwell, and Guest 1997). However, Goerger et al. (1998) concluded that inspecting an architectural floor plan of a building was more effective in creating a cognitive map than exploring a site through a virtual reality simulator. Danahy (2001) noted a visualization's ability to contextualize a view, instead of limiting the viewer to a single viewpoint and focus and Wergles and Muhar (2009) found that a computer visualization is effective at conveying both visual and spatial information. Appleton and Lovett (2003) found that increasing detail levels in the visualization resulted in increased viewer connectedness with the site and facilitated the viewer's ability to imagine they were physically on site. 
Constructivist theory suggests that students who use interactive visualizations would develop an improved understanding of a site because of their ability to control the learning process, and subsequently improve construction of their cognitive map. Research using visualizations bear this out. The ability to understand an object appears to be increased when the learner has active physical control of their view. Even digital objects, controlled through inputs such as a joystick or the keyboard, engages motor functions that leads to improved encoding of the information being viewed (James et al. 2001; Rountree, Hannah, and Wong 2002). Students who are active in the learning process also demonstrate improved encoding and understanding of information (Smart and Csapo 2007).

Furthermore, student enjoyment and engagement in the learning process is improved when students engage directly with the learning material instead of passively receiving it (Donovan and Bransford 2005; Mitsoni 2006). Giving students the ability to control the virtual tours should also lead to an increased level of ownership in the learning process and enable students to focus their study on elements of most interest to them (Driscoll 2005). Giving students more freedom to explore and focus their learning may seem foreign to history teachers, but it may provide students with the flexibility and control which they crave and, in the long term, serve as an important door to further exploration of the subject (Mitsoni, 2006).

Finally, the virtual tours would provide a means of access to historical sites that students would not have otherwise had. The intent of the virtual tours is comparable to the historical grand tour, with the students virtually following in the footsteps of so many before in an educational adventure to soak in the sites they have learned about. Such a physical journey would be financially unattainable to many students and academic institutions, but through the use of the virtual tours it was believed that students could receive many of the same benefits of physically visiting the sites without the financial cost.

Building on these past precedents, it was hoped that virtual tours would help students to better connect with history by allowing them to be virtually situated in a site. It was further theorized this would lead to improved understanding and appreciation of the spatial structure of the site and improve their understanding of how historical events and trends shaped the landscape (Brown, Collins, and Duguid 1989; Lebow and Wagner 1994). It was believed that the virtual tours would help to remedy some student disengagement because previous research had demonstrated that the use of panoramas and virtual artifacts increased student ownership of the learning material and improved student enjoyment of the learning process (Rountree, Hannah, and Wong 2002; Edsall and Wentz 2007).

Based on the research, two theories were developed regarding the impact of the virtual tours on student learning:

1. Student performance on spatial questionnaires for sites viewed using a virtual tour would be higher than sites viewed face-to-face.

2. Students would report higher levels of learner engagement when using the virtual tours than when using the face-to-face delivery. 


\section{Methodology}

To understand the impact of the virtual tours on student learning, a study was conducted in a face-to-face (F2F) landscape architecture history course $(\mathrm{n}=47)$ at an accredited landscape architecture program in the United States. There were 42 undergraduate students and 5 graduate students. Landscape architecture students composed the majority of the class (38 students).

The traditional presentation consisted of static pictures of a historic site delivered via a projector in a room with stadium seating. Each photograph was overlaid on a map of the site with an arrow indicating the location and viewing direction to provide students with spatial orientation. The virtual tours used in this study consist of a series of interconnected $360^{\circ}$ photographic panoramas, captured on location at each site. Within the panoramas are information hotspots that, when clicked, provide the viewer with textual, photographic, or video information related to the site and its features. Navigating between the panoramas is done through movement arrows displayed within an individual panorama that link to adjacent locations.

To measure the virtual tours' impact on student comprehension of the spatial organization and character of historic sites, a series of spatial questionnaires were administered to students. Prior to completing each questionnaire, students experienced a site through either the traditional lecture method or on their own via a virtual tour.

The spatial questionnaire consisted of a site map with a hypothetical walking route displayed on the map. The questionnaire was modeled on concepts of spatial awareness and cognitive mapping developed by Lynch (1960) and Wergles and Muhar (2009). Below the map, students were given a series of ten photographs displaying various points along the walking path, shown in a randomized order. Students were asked to order the photographs in the sequence they would encounter them along the walking path. The spatial questionnaires were delivered via computer within the university's Canvas learning management system. In total, students completed spatial questionnaires for eleven sites viewed using virtual tours and ten sites viewed face-to-face, for a total of 21 sites.

Sites were selected based on the availability of virtual tours on the Digital Library of Landscape Architecture History website and access to high quality photographs for the F2F sites. They were also selected to afford a broad range of sites representing different historic styles, spatial structure and size. Five pairs of sites, with one F2F site and one virtual tour site, were specifically singled out to provide as direct a comparison as possible between the two delivery methods. These paired sites were selected to be as comparable in style, structure, and size as possible (see Figure 1).

Results of the spatial questionnaires for the paired sites were statistically analyzed using a repeated measures ANOVA. Based on the result of this analysis, subsequent post-hoc tests were conducted to analyze the impact of the virtual tours in relation to a site's spatial structure and size. Site structure was analyzed using structural subsets of sites: architectonic, landscape, or a blend of the two. All 21 sites were ranked and categorized based on the principles of axial symmetry, architectural treatment of the landscape, and the presence of architectural structures in the landscape. The size of a site was calculated in acres and based on the portion of the site students were shown and tested on. 
A capstone survey was administered on the final day of class to measure student engagement using the virtual tours compared to the F2F presentation over the course of the semester. The survey consisted of ten questions each for both delivery methods, measured on a seven-point Likert scale, which were aggregated to provide a single engagement score. The survey was designed using questions modified from similar surveys by Pintrich and DeGroot (1990) and Fu, Su, and Yu (2000). Additional, openended questions gathered student feedback on their experience using the virtual tours. Forty students completed the survey.

After analyzing the results from both the spatial questionnaires and the capstone survey, interviews were conducted with students. The interviews were conducted using a semistructured format, where topics of discussion were generated from analysis of the questionnaire and survey results.

\section{Results}

A repeated measures ANOVA was used to compare student performance on the spatial questionnaires of the five paired sites. The result was statistically significant with a large effect size, $\mathrm{F}(1,9)=17.666, \mathrm{p}<.01, \mathrm{n}^{2}=.662$. An interaction effect between the paired sites and the delivery method was observed, $\mathrm{F}(1,36)=14.766, \mathrm{p}<.01, \eta^{2}=$ .621. Upon further examination it was found that students scored higher using the virtual delivery method on all pairings except the Japanese garden pair (see Figure 1). The mean difference between the virtual (.453) and F2F (.29) groups was an average of .163, which represented a $56 \%$ improvement in measured scores.

Because the Japanese pair was the only pair in which the sites exhibited a landscape spatial structure, the decision was made to analyze student performance based on the spatial structure of the sites. When the data is graphed, it is clear that the least discrepancy in scores between the delivery methods occurs on sites in the landscape category, while the largest discrepancy in scores occurs within architectonic sites (see figure 2). However, when graphed on a scatterplot we see there was no correlation between student score and site structure for F2F sites $\left(\mathrm{r}^{2}<.01\right)$, but a modest correlation exists amongst the virtual tour sites $\left(\mathrm{r}^{2}=.182\right)$ (see figure 3 ). These results suggest that the structure of a site has little impact on a student's spatial comprehension of a site learned in the traditional F2F setting, but site structure may have a notable impact on spatial comprehension of a site learned with a virtual tour.

Student performance was also analyzed based on site size. For the F2F sites $\mathrm{r}^{2}=.043$ and for the virtual sites $r^{2}=.013$. There was a negative correlation for the F2F sites and a positive correlation for the virtual site. The result is a modest, but noticeable widening in student performance as the size of a site increases. However, the data is heavily skewed towards smaller sites and, when only these sites are compared, there is no measurable difference in performance. 


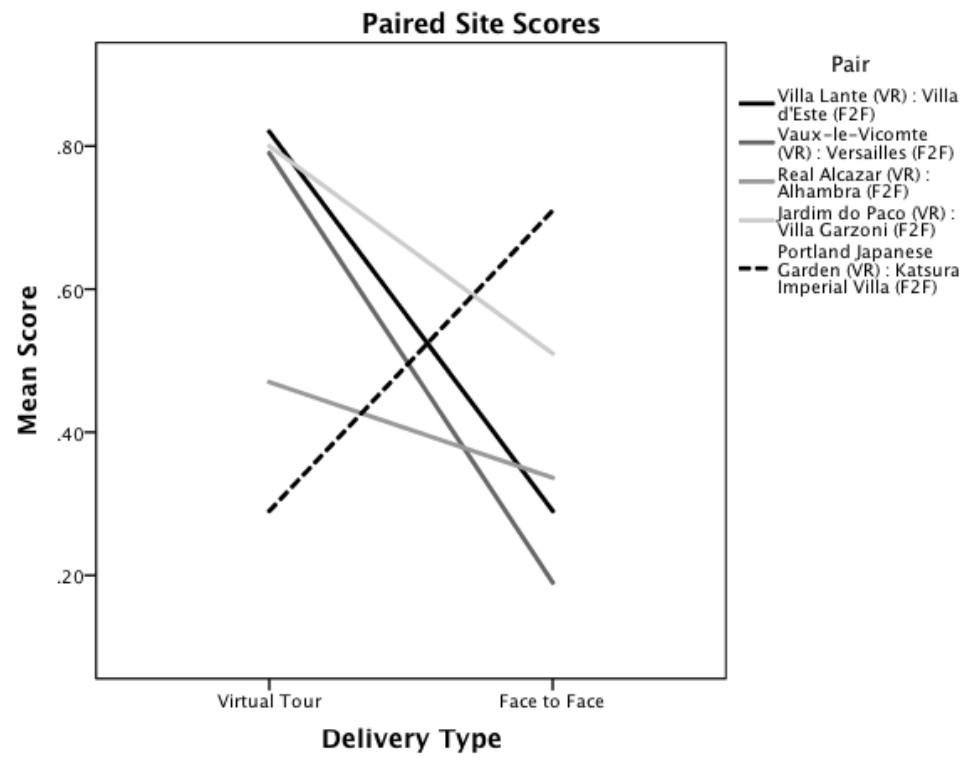

Figure 1: A comparison of mean scores for paired sites

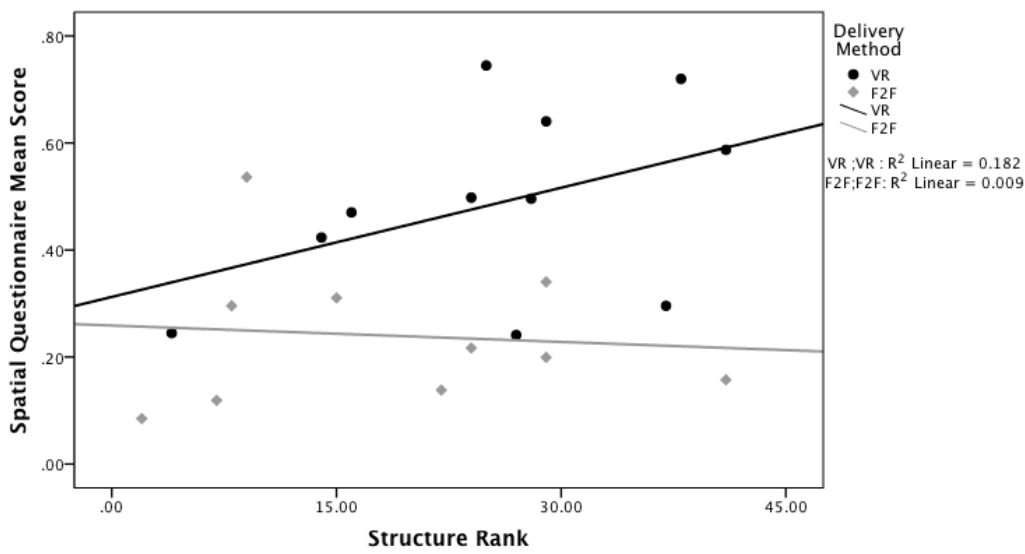

Figure 2: Scatterplot of spatial scores for sites, ordered by structural rank. Less structured, landscape sites are towards the left, and more structured, architectonic sites are found towards the right.

The capstone survey was used to measure student engagement in the learning process. Student engagement for the F2F and virtual methods was examined using a paired t-test and was not significant, $\mathrm{t}=-1.879(34) \mathrm{p}=.07$. The mean score of F2F was 5.26 and the mean score for the virtual tours was 4.93 . There was no significant correlation between engagement and performance on the spatial questionnaires $\left(\mathrm{r}^{2}<.01\right.$ for both methods). In the open-ended portion of the survey, students were asked to identify positive and negative aspects of the virtual tours. In general, the responses were overwhelmingly positive about the virtual tours. Responses were coded to provide clarity in analyzing the 
results. Students were especially positive about the virtual tours providing them with improved spatial encoding, better visual perception, control of the learning process, contextualization of historic information, and improved access to historical sites. Nearly one half $(47 \%)$ of respondents specifically stated that they believed the virtual tours improved their visual perception and understanding of the site and elements on it. Many of the negative student responses centered around technical or survey-related issues. Pedagogically, several students reported experiencing spatial disorientation while moving through the virtual tours and a small minority expressed frustration with the time commitment required to complete some virtual tours.

\section{Discussion}

The spatial arrangement of sites has historically been a significant indicator of humanity's relationship to the land - whether it be one of dominance, as was the case with the axially-dominant and architectonic landscapes of the Renaissance; conciliatory and reverent, as with the nature-mimicking landscapes of China and Japan; or interconnected, as with many modern landscapes with ecological emphasis. This dynamic and shifting relationship can be read in the landscapes of mankind as if a text. In the history course, there was significant emphasis placed upon analyzing and understanding the spatial quality of historic sites and is therefore a suitable analysis of student performance.

\subsection{Spatial Performance}

Students performed significantly better on the spatial questionnaires of sites that were viewed with the virtual tours, with the exception of the Japanese pair. This result might initially be explained by the greater amount of time students spent using the virtual tours. However, the benefit of the increased time spent looking at virtual tour sites is offset by the complexity of the site and ambiguity of potential walking routes students might be tested on. When viewing the F2F sites, students were shown a structured set of photographs and knew that the walking path would be solely based off the site locations they saw. When viewing the virtual tours, students had no such advantage, but had to rely on their ability to encode the site in its entirety in preparing to take the spatial questionnaire.

Evidence gathered through analyzing student performance on the spatial questionnaires and responses to the capstone survey indicate that the improved performance when using the virtual tours is a result of students encoding the virtual tour sites in a similar manner to physical sites. Danahy (2001) identified the ability to move around a site as being a key element in the viewer's ability to understand it. Such movement is not possible in the traditional lecture method. Many students specifically mentioned this ability to move through the site in their comments and did so using terms associated with physical presence. For instance, one student stated: "It was really helpful to get a feel for the layout of the site by being able to walk through it."

More important than simply traveling through a site is the ability to control your movement and interaction with the site. Having control of how you interact with the landscape is critical to building the context of what is being viewed (Danahy 2001). 
Additionally, having control over the viewing environment leads to better encoding of space and forms than passive methods of visualization, such as still photographs or video (James, et al. 2001). Several students specifically mentioned that the virtual tours were an improvement over pictures because of their ability to control their view and understand elements in context. This subsequently helped them understand the spatial construction of the site in addition to important historical facts and theories.

The virtual tours also provided students with multiple modes of representation for each site, including the interactive panoramas, plan view map, video, still photographs, sound, and textual information. Multiple representations of data can provide the viewer with a richer level of detail by presenting different, but complimentary, perspectives of the data (Ainsworth and VanLabeke 2004). The virtual tours also reinforced learning occurring in the lecture or textbook readings. Students found this aspect of the virtual tours to be particularly useful. One student commented that "it was easier to understand the concepts and styles we learned in class while looking at the virtual tour." Several others commented that the virtual tours provided them with a greater sense of the scale and spatial structure of sites than the lectures or textbook.

These modes of representation can also engage different senses, such as auditory, and invoke emotional and sensory responses similar to what a person would experience on site (Nash et al. 2000; Bishop and Rohrman 2003). Student comments suggested that the virtual tours produced such responses as they frequently refer to their experience using the virtual tours with emotive words such as peaceful, enjoyable, experiencing, connecting, and sensing.

The traditional lecture environment that represents the dominant landscape history pedagogy runs counter to landscape architecture student preference, and commonly turns students into passive receptors of information. Landscape architecture students typically prefer learning using an open-ended exploratory process that allows them to engage, experiment, and emotionally connect with the subject matter, and they perform better using a pedagogy that supports this type of learning (Brown, Hallett, and Stoltz 1994; Kvan and Yunyan 2005; Demirbas and Demirkan 2007). It would appear that the virtual tours are particularly well suited to teaching landscape architecture history because they provide students with this ability to explore and experiment within a historic landscape.

The results of student performance, based on the structural characteristics of a site, suggests that students constructed cognitive maps of the VR tour sites in a similar manner to which cognitive maps of physical sites are created. Student performance improved when sites were more architecturally structured. This is not unexpected, the more structured a site is, the more it possesses, to borrow from Lynch's (1960) typology, identifiable edges, paths, nodes, and landmarks. When moving through a physical environment it is these spatial cues that provide the basis for the construction of a cognitive map. The virtual tours recreate this same spatial awareness, and a student would be able to observe identifiable landmarks from various locations throughout the site, thereby aiding them in constructing a cognitive map of the site.

Student comments reinforced this theory, describing how the $360^{\circ}$ view provided them with the ability to reference different objects on the site, making it "easier to remember important elements." Another student commented on how the virtual tours allowed her 
to understand how the "elements [on the site] relate to each other." Many made statements that directly compared their experience viewing the virtual tours to physicality, and that this sense of presence made it easier for them to remember the sites. It appeared that the information hotspots in the virtual tours impacted students' abilities to remember particular elements, with multiple students commenting that the hotspots helped them to recall a certain object or location on the course exams. The hotspots may have created an additional layer of meaning for the associated object, which leads to improved memory of the object within the viewer's cognitive map (Lynch 1960).

Turning to the Japanese garden pair, this was the only pair in which students did not score significantly higher when using the virtual tour. Although Japanese gardens are deeply structured, that underlying structure is not readily apparent to the casual observer or novice, nor is it expressed in the traditional norms of order as codified in western cultures. At times, edges are ill-defined and paths enter and exit from view, making it difficult to determine which paths are connected and the termini of each. The lack of clearly-defined edges in the landscape may have been particularly disruptive as the removal of edges makes the estimation of scale and distance more difficult (Saleeb and Dafoulas 2010). Potential landmarks are often understated in order to create a naturalized landscape suited to quiet reflection. In this type of landscape, the virtual tours appear to benefit the student less, in regards to spatial awareness, as the improved cognitive mapping abilities are weakened by the structural characteristics of the site.

The relationship between delivery methods and performance, when measured by site size, is less pronounced. There is a small trend towards an increasing disparity in performance as site size increases. This may also be tied to how a student constructs a cognitive map of the site, as on large sites the edges and landmarks may become less noticeable, or so numerable, that they become difficult to remember or differentiate. It is likely that the increased number of paths on large sites, as well as the greater distances those paths cover, made it difficult for students to connect the entire site together in their mind. Lynch (1960) discovered that in order for people to create an accurate cognitive map of a location they needed knowledge of the origin and destination of the paths crossing the area. A student's ability to "walk" from the start to the end of paths in a virtual tour may partially explain the widening gap in performance between the two delivery methods as site size increased.

However, the data is skewed towards smaller sites ( $<6$ acres) and, when only these smaller sites are analyzed, there is no difference in student performance that can be attributed to variation in site size. More examples of larger virtual tour sites are needed before definitive conclusions can be made about the impact, if any, site size has on a student's ability to create a cognitive map using the different delivery methods.

\subsection{Student Engagement}

It was theorized that because the virtual tours permitted the student greater control over how they viewed and interacted with each site and the historical content, the virtual tours would increase student engagement in the learning process. However, the survey results did not bear this out, and instead revealed that student engagement measured lower when using the virtual tours. This result was surprising, especially given the overwhelmingly positive feedback received in the comments section of the same 
survey. To explore the dynamics of the impact the virtual tours had on learner engagement in more detail, interviews were conducted with students after the conclusion of the course.

The interviewed students were in agreement that the virtual tours were somewhat less engaging than the in-class lecture (but much more engaging than a textbook), but also believed the virtual tours had important benefits not available via a traditional lecturebased environment. The students viewed each virtual tour as a case study of a particular site and historic period and felt they provided a depth of information and opportunity for analysis that they didn't receive from the lecture or textbook. The virtual tours were successful in contextualizing each historic site, transforming them from an abstract site on the other side of the globe, inaccessible and often inconsequential beyond its existence in the curriculum, into an appreciable influence on the development of landscape design and the profession of landscape architecture.

Some of the students interviewed believed the engagement scores for the virtual tours would have been higher had the survey been administered earlier in the semester. This was based on the feeling that the virtual tours were used less often towards the end of the semester, and that this decrease fundamentally changed how the tours were perceived. Earlier in the semester the virtual tours were a learning element that was regularly used and anticipated by students. Towards the end of the semester, the decreased use may have caused students to view them more as additional homework than a core learning activity. An alternative explanation is that a novelty effect occurred, and student enthusiasm and engagement with the tours gradually decreased over the course of the semester as students became more familiar with using the virtual tours.

The information hotspots, which provided contextual information, were reported to be particularly useful and surprisingly engaging. The additional information helped to engage the student deeper with the site and also assisted the students to connect information learned during the lecture to a built example, thereby providing scaffolding for the learner to construct an understanding of the theories and styles. Evidence that the virtual tours were providing this understanding is found in the survey comments, in which many students commented on how they applied information from the virtual tours to their other classes. This cross-course integration of knowledge suggests a higherlevel of cognitive understanding (Eilouti 2007).

\section{Conclusion}

This study demonstrated the viability of integrating panoramic virtual tours into landscape architecture history pedagogy. The virtual tours were shown to improve student's spatial comprehension of historic sites and suggested that students engaged with the virtual sites in a manner similar to a physical site and contextualized the historic information. Although the virtual tours did not have a measurable improvement in student engagement, they were demonstrated to be functioning according to their theoretical and pedagogical intent to provide students with the opportunity to explore historic sites to develop a deeper understanding of historic theories and styles than would be possible in a traditional lecture-based environment.

The effectiveness of the virtual tours in the curriculum indicate that they are a valuable 
addition to landscape architecture history pedagogy and help students to connect to history in a meaningful manner that encourages exploration of the subject beyond the classroom. A well-developed virtual tour may be a superior replacement for textbook readings. It also suggests that virtual tours can provide institutions with a sustainable method to provide their students with an educational experience equivalent to an on-site visit and, while not intended as a complete replacement for physical site visits, the ability of virtual tours to easily, cheaply, and effectively connect students to geographically diverse sites should not be undervalued.

\section{References}

Ainsworth, S., \& VanLabeke, N. (2004). Multiple forms of dynamic representation. Learning and Instruction, 14, 241-255.

Appleton, K, \& Lovett, A. (2003). GIS-based visualisation of rural landscapes: defining "sufficient" realism for environmental decision-making. Landscape and Urban Planning, 65, 117-131.

Bishop, I. D., and Rohrmann, B. (2003). Subjective responses to simulated and real environments: a comparison. Landscape and Urban Planning, 65, 261-277.

Bliss, J. P., Tidwell, P. D., \& Guest, M. A. (1997). The Effectiveness of Virtual Reality for Administering Spatial Navigation Training to Firefighters. Presence-Teleoperators and Virtual Environments, 6(1), 7386.

Brown, J. S., Collins, A., \& Duguid, P. (1989). Situated cognition and the culture of learning. Educational Researcher, 18(1), 32-41.

Brown, R. D., Hallett, M. E., \& Stoltz, R. R. (1994). Student learning styles in landscape architecture education. Landscape and Urban Planning, 30, 151-157.

Carlucci, R. (2007). Multimedia and Websites. Journal of the Society of Architectural Historians, 66(3), 415-17.

Danahy, J. W. (2001). Technology for dynamic viewing and peripheral vision in landscape visualization. Landscape and Urban Planning, 54, 125-137.

Demirbas, O. O., and Demirkan, H. (2007). Learning styles of design students and the relationship of academic performance and gender in design education. Learning and Instruction, 17, 345-359.

Dewey, J. (1966). Democracy and Education. New York, NY: Free Press.

Donovan, S., \& Bransford, J. (Eds.). (2005). How Students Learn: History, Mathematics, and Science in the Classroom. Washington, DC: The National Academies Press.

Driscoll, M. P. (2005). Psychology of Learning for Instruction (3rd ed.). Boston, MA: Pearon.

Edsall, R., \& Wentz, E. (2007). Comparing Strategies for Presenting Concepts in Introductory Undergraduate Geography: Physical Models vs. Computer Visualizations. Journal of Geography in Higher Education, 31(3), 427-444.

Eilouti, B. (2007). A problem-based learning project for computer-supported architectural design pedagogy. Art, Design \& Communication in Higher Education, 5(3), 197-212.

Erstad, O. (2002). Norwegian students using digital artifacts in project-based learning. Journal of Computer Assisted Learning, 18, 427-437.

Fu, F., Su, R., \& Yu, S. (2009). EGameFlow: a scale to measure learners' enjoyment of e-learning games. Computers \& Education, 52, 101-12.

Goerger, S., Darken, R. P., Boyd, M., Gagnon, T., Liles, S., Sullivan, J., \& Lawson, J. (1998). Spatial knowledge acquisition from maps and virtual environments in complex architectural spaces. Proceedings of the 16th applied behavioral sciences symposium, 6-10.

Hartzler-Miller, C. (2001). Making send of "best practices" in teaching history. Theory \& Research in Social Education, 29(4), 672-92.

James, K. H., Humphrey, G. K., \& Goodale, M. A. (2001). Manipulating and Recognizing Virtual Objects: Where the Action Is. Canadian Journal of Experimental Psychology, 55(2), 111-120.

Kvan, T., \& Yunyan, J. (2005). Students' learning styles and their correlation with performance in architectural design studio. Design Studies, 26, 19-34. 
Land, S. M., \& Hannafin, M. J. (2000). Student-Centered Learning Environments. In D. H. Jonassen \& S. M. Land (Eds.), Theoretical Foundations of Learning Environments (pp. 1-24). Mahwah, NJ: Lawrence Erlbaum Associates.

Lebow, D. G., \& Wager, W. W. (1994). Authentic activity as a model for appropriate learning activity: Implication for design of computer-based simulations. Paper presented at the 1994 National Convention of the Association for educational Communications Technology Sponsored by the research and Theory Division, Nashville, TN, February 16-20.

Lynch, K. (1960). The Image of the City. Cambridge, MA: MIT Press.

Mitsoni, F. (2006). 'I get bored when we don't have the opportunity to say our opinion': learning about teaching from students. Educational Review, 58(2), 159-70.

Michael, S. E. (2007). The past as we show it: Trends in delivery of landscape architecture history. Paper presented at the Council of Educators in Landscape Architecture Conference. State College, PA.

Nash, E. B., Edwards, G. W., Thompson, J. A., \& Barfield, W. (2000). A review of presence and performance in virtual environments. International Journal of Human-Computer Interaction, 12(1), 1-41.

Ozcan, O. (1999). Education and interactive panorama-design in architecture. Proceedings of the Education and Research in Computer Aided Architectural Design in Europe Conference: Architectural Computing from Turing to 2000. Liverpool, UK.

Piaget, J. (1973). To Understand is to Invent: The Future of Education. New York, NY: Grossman.

Pintrich, P. R., \& DeGroot, E. V. (1990). Motivational and self-regulated learning components of classroom academic performance. Journal of Educational Psychology, 82, 33-40.

Rountree, J., Hannah, R., \& Wong, W. (2002). Learning to Look: Real and Virtual Artifacts. Educational Technology \& Society, 5(1), 129-134.

Rountree, J., Hannah, R., \& Wong, W. (2004). A fide-mediation framework for virtual objects. International Journal of Learning Technology, 1(2), 164-178.

Saleeb, N., \& Dafoulas, G. (2010). Analogy between Student Perception of Educational Space Dimensions and Size Perspective in 3D Virtual Worlds versus Physical World. International Journal of Engineering, 4(3), 210-18.

Smart, K. L., \& Csapo, N. (2007). Learning by doing: engaging students through learner-centered activities. Business Communication Quarterly, 70(4), 451-7.

Wergles, N., \& Muhar, A. (2009). The Role of Computer Visualization in the Communication of Urban design--A Comparison of Viewer Responses to Visualizations Versus On-site Visits. Landscape and Urban Planning, 91, 171-182.

Wilson, S., \& Wineburg, S. (1988). Peering at history through different lenses: The role of disciplinary perspectives in teaching history. Teachers College Record, 89(4), 525-39. 